\title{
Kitossa, T. (Ed.). (2021). Appealing because he is appalling: Black masculinities, colonialism, and erotic racism. University of Alberta Press. 536 pp. USD 49.99, ISBN: 9781772125535
}

\section{Martez Files $^{1}$}

I read this edited collection to understand how contemporary thinkers position the experiences, exploitation, limitations, and delimitations of Black men and boys. Digesting chapter after chapter, I was floored by their academic rigor and necessary complexity. I tend to be wary of texts claiming to undertake full-scope investigations of Black masculinity because I have mostly experienced such works as adversarial to the Black feminist tradition. Often scholars doing Black masculinity work begin their work with a critique of Black feminism and highlight the ways Black feminist analysis and interpretation have created some level of social harm for Black men and boys. This academic posture poses a challenge for Black masculinity scholars because it does not make space for digesting decades worth of scholarship written by Black feminists about Black men that are insightful and generative. For instance, bell hooks in We Real Cool: Black Men and Masculinity (2004) suggested, "[B]lack men are longing for love, and since that longing cannot be satisfied until they do recovery work, individual [B]lack men are eager to feel and heal, to process" (p. 131). All this to say, Black men are not insatiable blood-thirsty monsters waiting on their next victims, and some Black feminist scholars have given us language to understand that. The truth is that many Black men are longing to be seen, held, and loved. I agree with hooks' analysis because that was my experience and the truth for the countless Black boys I have raised and mentored. They want closeness, intimacy, and connection. They want to be understood as more than threat and menace. They want to be read as complex, nuanced, and multilayered beings. Powerfully, this text sets out to accomplish some of these goals

\footnotetext{
${ }^{1}$ University of Alabama at Birmingham, USA
} 
and more in a collection of writings from scholars across the globe who work to reify the lives and experiences of Black men and boys.

This volume is an interdisciplinary collection of essays that, at their foundation, employ the "psychosexual perspectives of Fanon and Baldwin to reframe dominant narratives of Black male experience" (p. xi). Indeed, Black men and boys exist on the periphery in gender studies. In response, some scholars, like masculinity scholar and Black feminism critic Tommy Curry, who penned the forward to this text, have responded by challenging the conventional understanding of this group by looking at empirical data and talking to Black men about their social, economic, political, and gendered experiences. In his opening, Curry (2021) unpacks the enduring legacy of misreading Black men and boys in academic literature. He argues that Black men are described in most social science research through the lens of "lack, hyper-masculinity, and sexism" (p. xi), and he shatters the age-old tropes of Black men as "violent sexual predators who take pleasure in the murder and rape of others" (p. xii). According to Curry, this was at the core of the 1960s and 1970s "sub-culture of violence" theories produced by White feminists and criminologists, which still lingers today. He speaks to how negative stereotypes and tropes allow for the genocide of Black men. Interestingly, he understands racism as a type of "misandric aggression" and calls this type of violence against Black men "sexspecific targeting" and "male gendercide" (p. xiv). While many of the assertions Curry makes are historically supported, and while I agree with much of his analysis, some of his cautions become elusive in their interpretation of Black feminist thought as a vehicle to the death and destruction of Black men and boys.

To be sure, some Black feminist scholars have written reductionally around the experiences of masc people, but that is not the aim of the Black feminist project. As hooks (2004) lamented on Black men, "[V]isions of [B]lack men as healers, able to nurture life, are the representations of [B]lack masculinity that 'keep it real' for they offer the vision of what is possible, a hint of the spirit that is alive and well in the [B]lack male collective being, ready to be reborn" (p. 132). Often one of the most critiqued Black feminist writers, here hooks offers generativity, possibility, and love for Black men. This contrasts with Curry's reading, which label Black feminists as unyielding participants in the desensitizing of the violence, especially sexual violence that Black men 
suffered under slavery and beyond. Here, I will boldly assert that while Curry's empirical research is sound, his conclusions are slippery and damaging. The Black masculinity studies project cannot be grounded in victimization narratives used to delegitimize how other Black groups, including women, femmes, queer, and trans folks, are also victimized and targeted. Instead, clear delineations must be made to, as Curry suggests, "reconfigure the boundaries of gender theory and thought itself, which remains deeply ingrained in various feminist-inspired accounts of a racist and anti-Black male imagery" (p. xxi). This anti-Black male imagery must be dismantled, and that is the floor of the socially transformative approaches necessary for more nuanced readings of Black men. However, in that dismantling, possibilities remain boundless for Black men and boys to imagine and build 'otherwise' their lives and livelihoods.

This collection has stunningly addressed the historical, political, and social implications underlying the Black male experience, not only in the United States but across the globe. The edited volume is divided into four parts related to various aspects of Black men and boys' global experiences and the ways they have been imagined or unimagined in the public imagination.

Part I, Erotic Racism, Tropes, and Interracial Sex: Art, Nations, and Transnationalism, commences with the editor's introduction. It constitutes Tamari Kitossa's personal account of the ways his own Black male body has been subjected to violence, sexual harassment, damaging psychic hits, and emotional abuse. In this, he positions a refusal of the gendered violence that Black men and boys suffer. Kitossa (2021) offers "Black Phallic Fantastic" to understand the object status of Black men and boys as appealing and appalling. His concept "encapsulates three core traits according to which Black men's (and boys') bodies are imagined and defined as priapic, hypersexual and prone to commit rape" (p. xlii). This departure is significant because it speaks to how sexualized racial patriarchy also impacts male bodies. Kitossa hopes this book serves to "cover as much of a transnational viewpoint on erotic constructions of Black men" (p. xlii) as possible. That is realized in the subsequent chapter - also by Kitossa - Can the Black Man Be Nude... which looks at 19th and 20th-century art, film, and media to highlight the attitudes and deadly effect that these pornographic, demonizing tropes have on Black men's lives and livelihoods. It is followed by Russell's Anaconda East, which looks at how Japanese cultural artifacts and descriptions render Black men 
pathological hypersexual beasts. It attends to "mythic Black manhood" that "spans the racial and sexual mythologies of both the 'East' and 'West" (p. 93), looking at Black men's representation by positioning Japanese women's sexual agency, Black men settling in Japan, Black men's depictions in Japanese pornography, and the simplistic ways that Black men are reduced to sexual deviants as a way to explain away their presence in Japan. Next, Deliovsky's White Femininity, Black Masculinity problematizes the sexually exploitative behaviours of White women who travel to certain countries seeking to find some Black orgasmic experience with foreign Black men-paying close attention to the "positional superiority of white women relative to their racialized other" (p. 132). This work challenges these White women's self-constructions as either "innocent or ignorant" (p. 132) and instead describes the ways that these behaviours are grounded in dehumanization and the thingification of Black men. In sum, Part I demonstrates a unique departure in understanding how the Black male body has been regarded and used as both an object of fear and loathing and as a tool of sexual exploration and exploitation.

Part II, What Does a Black Man Want? Situating the Lives of Black Men, commences with Hall's Beyond the Exotic and the Grotesque that deals with the way Black men have been seen, read and understood in the UK as both desired and despised. He sketches a theory of "radical Black men's love of self [and] offer[s] us the turn signals on the road to a moral philosophy grounded in the secularization of the Christian gospel" (p. 145); essentially building a "biblical and moral philosophy of self-inquiry" that can be used as a site of resistance and knowing. Moore and Kitossa's A Krip-Hop Theory works to bridge the gap between "the theorizations of Black disability and Black disablement" (p. 178). They introduce us to Krip-Hop theory based on Krip-Hop Nation - an intervention centered on "disability within Black communities and the larger context of Black history" (p. 189). This work puts disability at the center of resistance and social justice and "envisions Black disability as a site of empowerment" (p. 218). This offering is substantial because it highlights how men navigating anti-Blackness have layered and compounded suffering based on ableism. This offering strengthens the work of those hoping to do liberative and empowering social justice work. Overall, Part II pushes us to think about how disability studies and theological studies can be used to service the freedom and liberation of Black men and boys. 
Part III, National Culture, Transqueering Black Masculinities, and Challenging Hegemonic Masculinity, commences with McIntosh's Carrying Corporeal Narratives that employs intersectional theory to explore the "psychosocial effects of the anti-queer visual representations encountered by [lowerclass-Black-queer-males]" (p.235). The essay accomplishes this by looking at anti-queer caricatures and visual narratives in the popular newspaper Jamaican Observer. It primarily focuses on the works of famous caricaturist, Clovis Brown. It purports that these tropes and stereotypes of lower-classBlack-queer-males, as depicted by Brown, work to normalize the "violence toward Jamaican queers" (p. 235) and create anxiety invoking representations that lend to a social-cultural pathology of Black queer men in Jamaica. Poe's "A Quare Eye to Slavery" uses James Baldwin's "terror of the flesh" and E. Patrick Johnson's "quare theory" to explore same-sex relations amongst the enslaved (p. 266). Poe notes that the language used to describe same-sex relationships is not as easily decipherable and that a distinction needs to be made between exploitation and same-sex desires that were present during the transatlantic slave trade. This work is an attempt to understand the homoerotic desires of racism as well as how homosexuality might be understood outside of Eurocentric renderings. Poe highlights that the rise of the LGBTQ aesthetic, identity, and politic problematizes conversations around Black queer males because same-sex experience have been seen as some type of modern or Eurocentric phenomenon. Poe offers E. Patrick Johnson's "quare" to help us expose the way quareness of Black men during the transatlantic slave trade is more a "same-sex desire rooted in the complex histories of African and African descendant people" (p. 281). Brilliantly, Poe argues that this matter moves beyond simply telling stories but recuperating the complexities and simplicities that seek to challenge us. Howard's 7 Eleven looks at how poor working-class men in Jamaica's garrison communities have both overcome and remained locked in toxic masculinity. Howard argues that Garrison culture and the Kingston music culture have worked to objectify women and leave men bound by patriarchal expectations. Howard offers a strong critique of masculinity to describe the context in which trendsetting artists such as Dexta Daps have resisted the official morality of middle-class mores and sexual norms which are often a part of Jamaican culture. The work looks at the ways that this music can both damage Black people but also liberate them from the shackles of 
patriarchal expectations. This collection of essays works to dismantle commonly accepted readings of Black men and boys, especially those that are queer and trans, and works towards new possibilities for their Black futures.

Part IV, The Other Other and the Black Man: Hot Sex and the Black Man in the Global South, features an essay by Satwinder Rehol and a co-authored piece by Tamari Kitossa, Elishma Khokhar, and Mohan Siddi. Rehol's "Sila ay Maliki" uses Fanon's Black Skin, White Masks as a framework to theorize around the Philippines' commonly used sports phrase "sila ay miliki" meaning "they are big" which Rehol reads as double entendre for the Black athletes being referenced. He argues that this is a "productive site for homoerotic reproduction" of a more "nativist hegemonic Filipino masculinity" (p. 319) that is more in keeping with a national consciousness and acceptability of masculinist portrayals. Even more, this work attends to racialized media scripts of these Black male athletes that function to ultimately reduce them to "pornotropic" and "phallic" symbols (p. 346). Ultimately, this research argues that the notion of "they are big" reduces Black men, as Fanon has described, from beings to only "penis." This dehumanization does damage to all those who encounter these tropes around Black male athletes. This work is followed by Kitossa, Khokhar, and Siddi's essay entitled "A Fanonist Reading of Anti-Black Sexual Racism in the Indian Imaginary" which traces the African contours of Anti-Blackness to sexual tropes of Black men in the context of Hindi superiority and Indian nationalism. It looks at the experiences of Siddi's (ethnic group in India and Pakistan), African students, and immigrants in India to understand their collective experiences. This work deals with the violent nationalist tropes surrounding these Black men, which the authors, drawing on Fanon read as "erotic racism" (p. 389). It explores how these ideas about Black men stand in conflict with the idea of "timeless" India and illuminates how this "erotic racism" renders Black men both appealing and appalling and exposes the problematics of an Indian national consciousness grounded in a "civilized" and "timeless" India that is devoid of Blackness. Together, these essays help us understand the harm of reading Black men and boys through pornotropic and erotically racist lens particular in the Asian and Eastern world.

Kitossa and the contributing authors have demonstrated a powerful example of reading Black men and boys in generative and restorative ways. Interestingly, Baldwin's and Fanon's cultural and psychoanalytic 
interpretations of Black masculinities add a profound level of criticality to these essays. I recommend this book for scholars, activists, organizers, and those interested in contemporary developments in Black masculinity studies. This book is a departure from conventional wisdom around Black men and boys and makes space to explore their lived experiences and identities. Recognizably, some of the ways the authors have presented information are in keeping with the Black radical tradition, which might be a drawing for many readers. Those trained in the Black feminist tradition, however, might be concerned with the ways Black feminism has been read and understood by some authors in the budding field of Black masculinity studies. However, I argue there is a dialectical relationship between the ways we understand the experiences of Black men and boys and the experiences of Black women and girls and Black trans, queer, non-binary people all of whom exist in complexity and unyielding nuance. This volume forces the reader to reconceptualize prior understandings and relations to gender studies and gender theory. Undoubtedly, this text will be a seminal work for those hoping to work at the intersections of race, class, and gender - especially those doing that work from a global perspective.

\section{Reference}

hooks, b. (2004). We real cool: Black men and masculinity. Taylor \& Francis.

Kitossa, T. (Ed.). (2021). Appealing because he is appalling: Black masculinities, colonialism, and erotic racism. University of Alberta Press. 